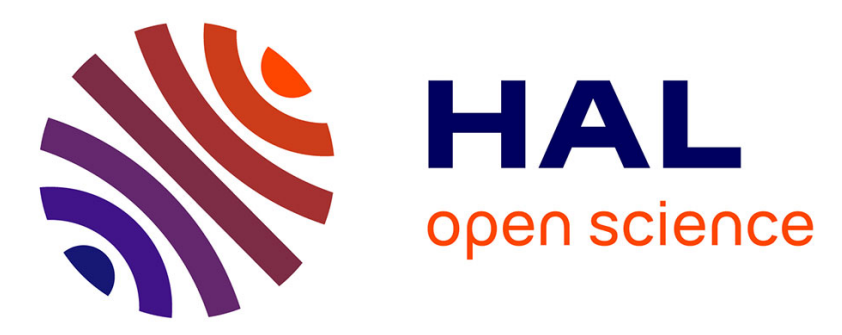

\title{
Bicatalyzed Three-Component Stereoselective Decarboxylative Fluoro-Aldolization for the Construction of Elongated Fluorohydrins
}

Adrien Quintard, Jean Rodriguez

\section{- To cite this version:}

Adrien Quintard, Jean Rodriguez. Bicatalyzed Three-Component Stereoselective Decarboxylative Fluoro-Aldolization for the Construction of Elongated Fluorohydrins. ACS Catalysis, 2017,7 (8), pp.5513-5517. 10.1021/acscatal.7b02353 . hal-01687102

\section{HAL Id: hal-01687102 https://hal.science/hal-01687102}

Submitted on 18 Jan 2018

HAL is a multi-disciplinary open access archive for the deposit and dissemination of scientific research documents, whether they are published or not. The documents may come from teaching and research institutions in France or abroad, or from public or private research centers.
L'archive ouverte pluridisciplinaire HAL, est destinée au dépôt et à la diffusion de documents scientifiques de niveau recherche, publiés ou non, émanant des établissements d'enseignement et de recherche français ou étrangers, des laboratoires publics ou privés. 


\section{Bicatalyzed Three-Component Stereoselective Decarboxylative Fluoro-Aldolization for the Construction of Elongated Fluorohydrins}

Adrien Quintard*๑ and Jean Rodriguez

Aix Marseille Univ, CNRS, Centrale Marseille, iSm2, Marseille, 13397, France

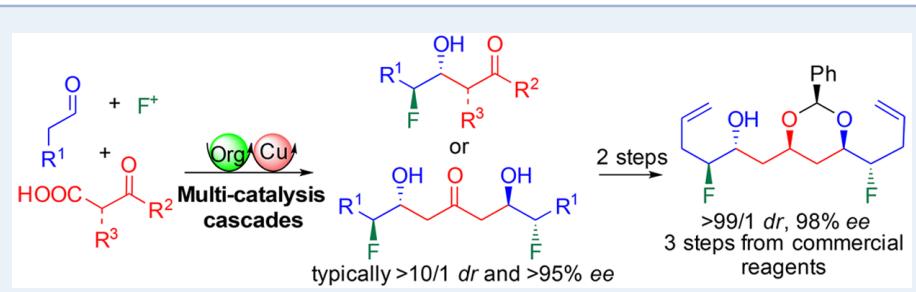

ABSTRACT: A bicatalyzed three-component cascade between simple aliphatic enolizable aldehydes, a fluorine source, and keto acids has allowed the diastereoselective and enantioselective direct synthesis of carbonyl-elongated vicinal fluorohydrins. The obtained complex acyclic functionalized molecules, possessing up to four stereogenic centers controlled in usually $>95 \%$ ee, hold great promise for further synthetic developments and rapid incorporation in bioactive elaborated structures.

KEYWORDS: enantioselectivity, fluorination, copper catalysis, organocatalysis, cascade

7 he stereoselective incorporation of fluorine into biologically active scaffolds is of the greatest importance for the development of drugs with perfectly designed bioactivity and bioavailability while relying greatly on laboratory-designed methodologies. ${ }^{1}$ However, the current synthetic organic chemistry toolbox is still limited hampering the straightforward stereoselective construction of defined complex bioactive fluorinated chemical architectures in a waste-free approach. ${ }^{2}$

In this context, polyketides and statins are among the most important classes of compounds regarding their bioactivity with an astonishing number of natural products and drugs incorporating the 1,3-polyol motif in their structure. ${ }^{3}$ Unfortunately, despite the influence of this motif in drug discovery and the promise of improved bioactivity resulting from fluorine incorporation, such modulation has largely been neglected, because of the lack of simple efficient approaches (Scheme 1a). ${ }^{4}$

Indeed, in this specific case, the main difficulty is to control the formation and the stereochemistry of a key carbonylelongated fluorohydrin structure by using standard techniques mainly based on aldolizations. ${ }^{5}$ Most of the research in this field has focused on the reactivity of preformed racemic fluorinated pro-nucleophiles in diastereoselective transformations, which resulted in a narrow scope. ${ }^{6}$ Only very recently, the Wennemers group proposed an enantioselective organocatalyzed version of this approach, requiring five steps for the preparation of the fluorinated pro-nucleophile and suffering a substantial decreased enantiocontrol as soon as key aliphatic aldehydes are involved (Scheme $1 \mathrm{~b})$. $^{7}$

On the other side, the complementary aldolization on preformed enantioenriched fluorinated aldehydes has been largely overlooked and remains challenging, allowing access to
Scheme 1. Proposed Bicatalyzed Enantioselective Synthesis of Fluorohydrins

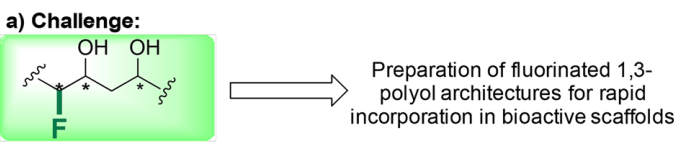

$$
\text { b) Use of fluorinated pro-nucleophiles: }
$$

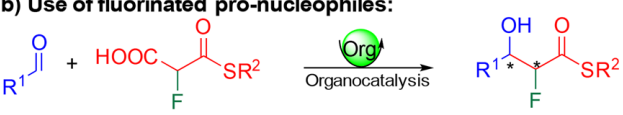

c) Stepwise stoichiometric aldolization:
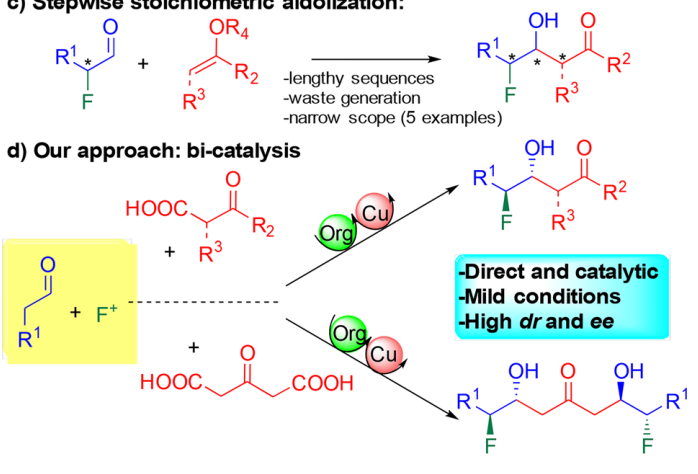

only a limited number of vicinal fluorohydrins in lengthy stoichiometric sequences (Scheme 1c). ${ }^{8,9}$ In view of a better 
incorporation of fluorine into polyols scaffolds, all of the abovementioned limitations-notably, the single access to simple vicinal fluorohydrins-clearly highlight the need for moregeneral methods. This would offer new synthetic opportunities for the construction of complex extended structures notably by introducing a bidirectional dimension to the strategies (Scheme 1d).

While highly desirable, the challenge of developing a direct and general eco-compatible route to synthetically valuable carbonyl-elongated fluorohydrins implies both the rapid generation of particularly volatile and configurationally unstable fluorinated aldehydes and their selective aldolization, ideally catalytically.

By taking advantage of a multicatalytic approach, ${ }^{10}$ we felt that it might be possible to envisage merging in a multicomponent approach an organocatalytic enantioselective $\alpha$ fluorination of aldehydes described by the groups of Jørgensen, MacMillan, Barbas, and Enders, ${ }^{11}$ with a diastereoselective metal-catalyzed aldolization (Scheme 1d). The implementation of such innovative bicatalytic strategy would require the development of a waste-free selective aldolization method occurring rapidly and under mild conditions to avoid fluorinated aldehyde racemization/decomposition facilitated by the increased acidity of the fluorine vicinal proton.

Herein, we present the results of our efforts toward the development of a new bicatalytic three-component diastereoselective and enantioselective decarboxylative fluoro-aldolization using widely available achiral substrates and combination of simple organocatalysts with Lewis acids. By extending the reactivity to a challenging bidirectional aldolization, our general strategy has culminated in the cascade synthesis of highly functionalized acyclic compounds bearing vicinal fluorohydrin motifs and up to four stereogenic centers, including two fluorinated ones. Excellent diastereocontrol and enantiocontrol were observed providing a rapid route to complex fluorinated polyols building blocks that are inaccessible using other techniques.

As mentioned in the beginning of this paper, the key to the development of the bicatalytic sequence requires identification of a selective aldolization that is compatible with the initial fluorination using diaryl-prolinol silyl ether $(S)$-cat1 as a organocatalyst and NFSI (2) as an electrophilic fluorine source, keeping in view the amenability to a bidirectional reactivity (see Table 1). ${ }^{1 \text { a }}$

Preliminary attempts at performing the addition of simple ketones using enamine catalysis failed, which led to the decomposition of the intermediate aldehyde. ${ }^{12}$ Decarboxylative aldolizations have recently appeared as interesting ecocompatible alternatives to classical aldolization methods, because of the ease of formation and fast reaction of the transient enolate under mild conditions and, in addition, generating only $\mathrm{CO}_{2}$ as a side product. ${ }^{13}$ The first experiment performed in a consecutive manner involving isovaleraldehyde (1a) and 3-oxo-3-phenylpropanoic acid (3a) without any additional catalyst (cat2) for the aldolization afforded only trace amount of the product (see entry 1 in Table 1). We next turned our attention to the use of tertiary amines as potential organocatalysts for the decarboxylative aldolization (entries 25 in Table 1). ${ }^{14}$ Gratifyingly, the addition of either triethylamine, quinine, or Takemoto Urea Catalyst (TUC) all provided the expected product $4 \mathbf{a}$ with low to moderate yield (23\%$50 \%)$ and promising diastereocontrol (3/1 to $8 / 1 \mathrm{dr})$, albeit with low enantiocontrol ( $\leq 72 \%$ ee, entries $2-5$ in Table 1$)$.
Table 1. Optimization of the Bicatalytic Process ${ }^{a}$

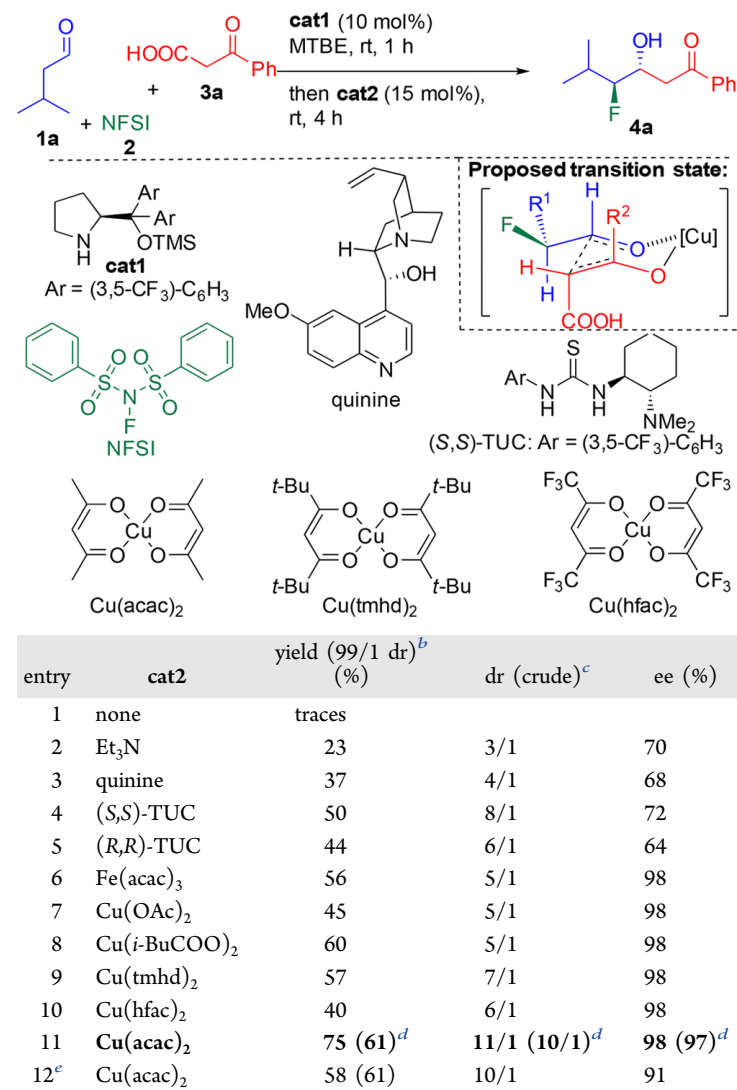

${ }^{a}$ All reactions performed using $0.2 \mathrm{mmol}$ of $1 \mathrm{a}, 0.22 \mathrm{mmol}$ of 2 , and $0.26 \mathrm{mmol}$ of $3 \mathrm{a}$. ${ }^{b}$ Yield of isolated single diastereomer. ${ }^{c}$ Determined by ${ }^{19} \mathrm{~F}$ NMR on the crude reaction mixture. ${ }^{d}$ Performed on larger scale using $1 \mathrm{mmol}$ of $1 \mathrm{a} .{ }^{e}$ Performed with a different reagent ratio using $0.24 \mathrm{mmol}$ of $1 \mathrm{a}, 0.2 \mathrm{mmol}$ of 2 , and $0.26 \mathrm{mmol}$ of $3 \mathrm{a}$.

This disappointingly low enantiocontrol, given the known efficiency of the initial $\alpha$-fluorination, mostly providing products with $>90 \%$ ee, ${ }^{11 a}$ highlights the difficulty to avoid the racemization of the sensitive fluoro-aldehyde intermediates.

In an attempt to solve this challenge, we sought to replace the organocatalytic activation for the aldolization by an alternative use of Lewis acids. ${ }^{15}$ For this purpose, we screened several inexpensive iron and copper complexes in this sequence. Confirming our hypothesis, all the screened Lewis acids performed well, avoiding the racemization of the intermediate aldehyde. As a result, the targeted functionalized vicinal fluorohydrin $4 \mathrm{a}$ was formed in $45 \%-75 \%$ yield with, in all cases, 98\% ee (see entries 6-11 in Table 1). In terms of diastereoselectivity, $\mathrm{Cu}(\mathrm{acac})_{2}$ turned out to be the best, providing $4 \mathrm{a}$ in $11 / 1 \mathrm{dr}$ vs $5 / 1 \mathrm{dr}$, using $\mathrm{Fe}(\mathrm{acac})_{3}$ for example (see entry 11 vs entry 6 in Table 1). Larger-scale experiments proved satisfactory, resulting in the final product formation in $61 \%$ yield and $97 \%$ ee (entry 11 in Table 1 ). Interestingly, when changing the $1 \mathrm{a} / 2$ ratio from $1 / 1.1$ to $1.2 / 1$, a reduced enantiocontrol was observed on the final product (91\% ee, entry 12 in Table 1). This observation is in accordance with the mechanistic observation by Jørgensen of a kinetic resolution of 
fluorinated aldehydes in the presence of excess NFSI during the formation of difluorinated aldehydes. ${ }^{16}$

Mechanistically, mass spectroscopy monitoring during the reaction indicated that the decarboxylation was occurring after the aldolization. The excellent diastereocontrol observed using $\mathrm{Cu}(\mathrm{acac})_{2}$ led us postulate a Cornforth-Evans cyclic transition state where minimization of dipole-dipole interactions would favor the formation of the anti adduct (see Table 1).,

With the optimized conditions in hand, we next decided to check the generality of our approach, a crucial parameter for its future implementation to drug discovery (Scheme 2).

Scheme 2. Scope of the Bicatalytic Decarboxylative FluoroAldolization Cascade

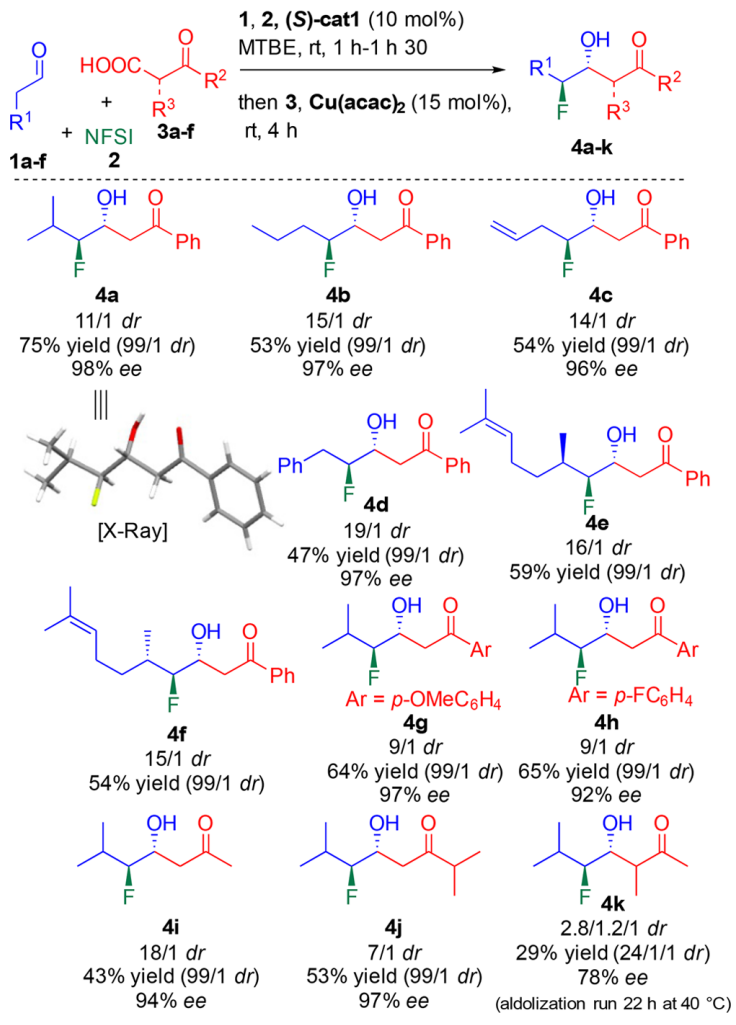

Interestingly, the process worked equally well using variously substituted aldehydes. The introduction of a linear alkyl substituent (4b), alkenyl (4c), or aromatic (4d) was possible in $47 \%-54 \%$ yield, $\geq 14 / 1 \mathrm{dr}$, and $96 \%-97 \%$ ee. Starting from pre-existing stereocenters as in $(R)$ - or $(S)$-citronellal, the process was entirely diastereodivergent, providing $\mathbf{4 e}$ and $\mathbf{4 f}$ in equal efficiency $(\geq 15 / 1 \mathrm{dr})$. In addition, other aromatics and aliphatic keto-acids could also be applied to the synthesis of fluorinated aldol products $\mathbf{4 g}-\mathbf{4 k}$. Different aromatic $(\rho$-OMe (4g), $\rho$-F (4h)) or aliphatic keto acids $(\mathrm{Me}(4 \mathbf{i}), i-\operatorname{Pr}(4 \mathbf{j}))$ allowed the formation of the expected products in $\geq 7 / 1 \mathrm{dr}$ and $\geq 92 \%$ ee. The only apparent limitation, in terms of keto-acids, appears when using sterically more congested $\alpha$-substituted keto-acid. In this case, $4 \mathbf{k}$ is formed after $22 \mathrm{~h}$ at $40{ }^{\circ} \mathrm{C}$ in decreased enantiocontrol ( $78 \%$ ee).

Of crucial interest, in all cases, the minor diastereomer was easily separated from the major one, allowing the isolation of the single anti adduct, $\mathrm{X}$-ray structure of $\mathbf{4 a}$ proving the relative and absolute configurations of the obtained aldol adducts (see Scheme 2). ${ }^{17}$

As mentioned in the beginning of this work, one of the great challenges facing organic chemists is the fast and stereoselective generation of complex scaffolds, notably in the acyclic series. With our general bicatalytic method in hand, we wondered if this type of reactivity could be extended to the direct generation of even more complex architectures by introducing a bidirectional dimension to the aldolization. ${ }^{18}$ Despite the fact that this would allow rapid access to synthetically important keto-diols, which are present in several natural products but also direct precursors of elongated 1,3-polyols or spiroketals (vide infra), enantioselective catalytic bidirectional aldolizations have barely been explored with a noticeable lack in the case of aliphatic aldehydes. ${ }^{19}$ In this context, we hypothesized that using an inexpensive keto-diacid (5) should advantageously allow the direct preparation of complex keto bis-vicinal fluorohydrins scaffolds (6) possessing four stereocontrolled acyclic stereocenters, which constitutes a substantial synthetic challenge (see Scheme 3). The obtained building blocks

Scheme 3. Bidirectional Bicatalytic Three-Component Synthesis of Keto-Diols (6)

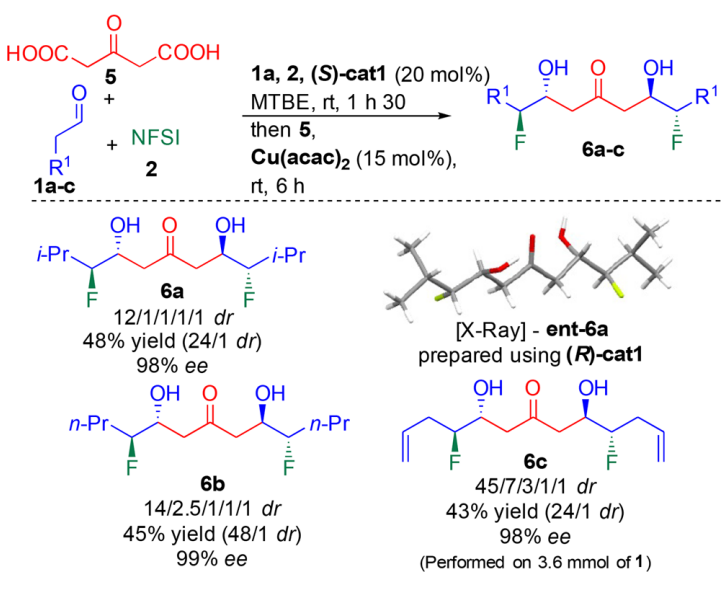

prepared in a simple one-pot sequence would be readily available for incorporation in complex bioactive skeletons. Despite the complexity of the sequence, the bicatalytic threecomponent process was amenable to bidirectionality furnishing keto-diols $\mathbf{6 a}-\mathbf{6 c}$ in $43 \%-48 \%$ yields (see Scheme 3). Moreover, the four stereogenic centers could be efficiently controlled, leading to the isolation of the major diasteromers in 98\%-99\% ee, thus solving the challenge of the generation of multiple acyclic stereocenters in a single process. The $\mathrm{C}_{2}$ symmetric character of the keto-diols was confirmed by X-ray analysis of ent-6a also obtained in $98 \%$ ee. Since no diastereoselection is observed while performing the reaction with $\mathrm{Cu}(\mathrm{acac})_{2}$ on the corresponding aliphatic aldehydes, ${ }^{15 \mathrm{~g}}$ this clearly suggests that the high diastereocontrol is due exclusively to the presence of the fluorinated stereocenter and not a 1,5-diastereocontrol. Interestingly, X-ray analysis indicated that the alcohols and $\mathrm{F}$ atoms were conformationally locked in an anti relationship with a strong intramolecular hydrogen bonding occurring between the two alcohols and the central ketone. 
With a variety of enantio-enriched vicinal fluorohydrins in hand, several derivatizations were undertaken to highlight the synthetic relevance of the developed strategy (Scheme 4).

Scheme 4. Derivatizations of the Aldolization Products

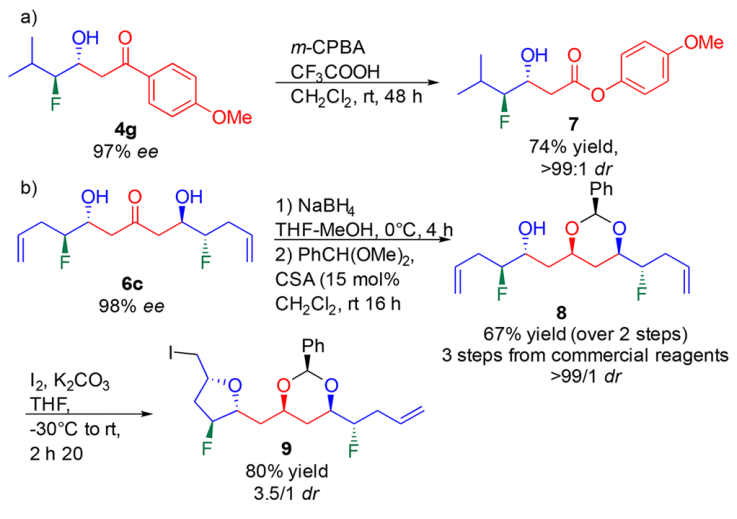

Beside Baeyer-Villiger oxidation of $\mathbf{4 g}$ allowing the preparation of ester 7 readily available for further chain elongation, ${ }^{20}$ we focused our attention on the desymmetrization of keto-diols, notably $\mathbf{6 c}$, possessing two additional alkenes functions. Simple $\mathrm{NaBH}_{4}$ ketone reduction, followed by desymmetrization by chemoselective acetalization of the syn-1,3-diol function, ${ }^{21}$ rapidly formed the protected bis-fluorinated 1,3,5-triol (8) in excellent stereocontrol and in only three steps from commercially available simple achiral substrates and reagents. The fluorohydroxy olefin 8 seems to be a highly promising building block for future chain elongation and incorporation into complex 1,3-polyols. Indeed, it possesses two differentiated alkenes that are readily available for further derivatization. To demonstrate this potential, we performed the iodo-etherification of 8 to 9 possessing seven stereocenters and three halogen functions in $80 \%$ yield and a $3.5 / 1 \mathrm{dr}$. In addition to this iodo-etherification, other transformations such as metathesis, alkene oxidation, or allylic oxidation can be envisaged, ensuring a rapid chain growth and incorporation into bioactive skeletons.

Finally, to test the robustness and the limits of the current system, we attempted to perform the direct cascade reaction by mixing all the reactants at the onset (Scheme 5). Gratifyingly, despite the presence of numerous nucleophilic and electrophilic positions on the different substrates, the cascade products $4 \mathrm{a}$, $\mathbf{4 b}, \mathbf{4 c}, \mathbf{4 h}$ were formed in $49 \%-70 \%$ yield and with same levels of diastereocontrol and enantiocontrol as in the consecutive procedure $(\geq 10 / 1 \mathrm{dr}$ and $\geq 93 \%$ ee). Even the challenging bidirectional cascade proved efficient, allowing the isolation of the single $6 \mathrm{a}$ in $98 \%$ ee.

This cascade is interesting not only in terms of complexity generated but also in terms of mechanism. It demonstrates the perfect chemoselectivity of the different catalysts able to achieve selective chemical function activations with adequate kinetics in such a complex mixture. It means that the kinetics of fluorination and the aldolization of fluoroaldehydes intermediates are faster than the aldolization of the starting aldehyde or the keto-acid fluorination. ${ }^{22}$ Such a highly selective cascade would be inconceivable by using other nucleophilic trapping reactions and opens interesting perspectives in the case where highly sensitive fluorinated aldehydes should be involved.
Scheme 5. Bicatalytic Three-Component FluoroAldolization Cascade

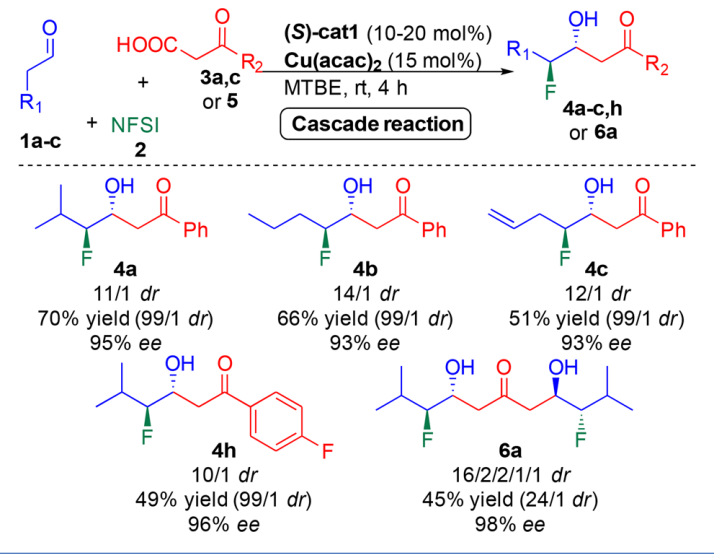

In conclusion, by efficiently combining an organocatalyzed fluorination with a copper-catalyzed aldolization, here, we report a general direct eco-compatible enantioselective method to access crucial optically active vicinal fluorohydrins with excellent diastereocontrol and enantiocontrol. This innovative one-pot single cascade allows the construction of complex fluorinated architectures, possessing up to four controlled acyclic stereocenters in up to $98 \%$ ee, which constituted a longsought-after synthetic challenge. In addition, the experimentally simple scalable procedure either in a consecutive manner or in a multicomponent fashion occurs under mild conditions (nondried and nondegassed solvents, room temperature) and using widely available substrates and catalysts.

As a result, we hope that this innovative strategy will inspire the chemistry community to easily incorporate fluorinated fragments such as $\mathbf{6 c}$ into bioactive compound designs. Moreover, given the mild conditions and high selectivities, other cascades involving such decarboxylative aldolization should be discovered in the near future.

\section{AUTHOR INFORMATION}

\section{Corresponding Author}

*E-mail: adrien.quintard@univ-amu.fr. ORCID $\odot$

Adrien Quintard: 0000-0003-0193-6524

\section{Author Contributions}

The manuscript was written through contributions of all authors. All authors have given approval to the final version of the manuscript.

Funding

The Centre National de la Recherche Scientifique (CNRS) and the Aix-Marseille Universite (AMU), the Agence Nationale pour la Recherche (No. ANR-13-PDOC-0007-01), are gratefully acknowledged for financial support. 


\section{Notes}

The authors declare no competing financial interest.

\section{ACKNOWLEDGMENTS}

The authors warmly thank Marion Jean and Nicolas Vanthuyne (Aix-Marseille Université-CNRS) for chiral-phase HPLC analysis and Michel Giorgi (Aix-Marseille Université-CNRS) for X-ray analysis.

\section{REFERENCES}

(1) (a) Muller, K.; Faeh, C.; Diederich, F. Science 2007, 317, 18811886. (b) Purser, S.; Moore, P. R.; Swallow, S.; Gouverneur, V. Chem. Soc. Rev. 2008, 37, 320-330. (c) O'Hagan, D. Chem. Soc. Rev. 2008, 37, 308-319. (d) Wang, J.; Sánchez-Roselló, M.; Aceña, J. L.; del Pozo, C.; Sorochinsky, A. E.; Fustero, S.; Soloshonok, V. A.; Liu, H. Chem. Rev. 2014, 114, 2432-2506.

(2) For the challenges associated with fluorine insertion, see: (a) Cahard, D.; Xu, X.; Couve-Bonnaire, S.; Pannecoucke, X. Chem. Soc. Rev. 2010, 39, 558-568. (b) Furuya, T.; Kamlet, A. S.; Ritter, T. Nature 2011, 473, 470-477. For a recent overview on enantioselective fluorine insertion, see: (c) Yang, X.; Wu, T.; Phipps, R. J.; Toste, F. D. Chem. Rev. 2015, 115, 826-870.

(3) (a) Rohr, J. Angew. Chem., Int. Ed. 2000, 39, 2847-2849. (b) Koskinen, A. M. P.; Karisalmi, K. Chem. Soc. Rev. 2005, 34, 677690 .

(4) (a) Walker, M. C.; Chang, M. C. Y. Chem. Soc. Rev. 2014, 43, 6527-6536. (b) Walker, M. C.; Thuronyi, B. W.; Charkoudian, L. K.; Lowry, B.; Khosla, C.; Chang, M. C. Y. Science 2013, 341, 1089-1094. (c) Wang, Z.; Cheng, L.; Kai, Z.; Wu, F.; Liu, Z.; Cai, M. Bioorg. Med. Chem. Lett. 2014, 24, 3869-3876.

(5) Trost, B. M.; Brindle, C. S. Chem. Soc. Rev. 2010, 39, 1600-1632. (6) For the most significant examples, see: (a) Welch, J. T.; Seper, K.; Eswarakrishnan, S.; Samartino, J. J. Org. Chem. 1984, 49, 4720-4721. (b) Saadi, J.; Akakura, M.; Yamamoto, H. J. Am. Chem. Soc. 2011, 133, 14248-14251. (c) Saadi, J.; Yamamoto, H. Chem.-Eur. J. 2013, 19, $3842-3845$.

(7) Saadi, J.; Wennemers, H. Nat. Chem. 2016, 8, 276-280.

(8) For a review on the chemistry of halogenated aldehydes, see: (a) Britton, R. Kang, B. Nat. Prod. Rep. 2013, 30, 227-236. In contrast to fluorinated aldehydes, the aldolization of chlorinated aldehydes has been extensively studied; see, for example: (b) Kang, B.; Mowat, J.; Pinter, T.; Britton, R. Org. Lett. 2009, 11, 1717-1720. (c) Borg, T.; Danielsson, J.; Somfai, P. Chem. Commun. 2010, 46, 1281-1283. (d) Halperin, S. D.; Britton, R. Org. Biomol. Chem. 2013, 11, 1702-1705. The relative poor stability of chlorinated aldehydes has inspired a DKR process by aldolization; see: (e) Bergeron-Brlek, M.; Meanwell, M.; Britton, R. Nat. Commun. 2015, 6, 6903-6907.

(9) Using this approach, only five different enantioenriched fluorohydrin were prepared: see ref 7 and (a) Díaz-Oltra, S.; Carda, M.; Murga, J.; Falomir, E.; Marco, J. A. Chem. - Eur. J. 2008, 14, 92409254. For other examples on aldehydes with a tetra-substituted fluorinated carbon center, see: (b) Yamazaki, T.; Yamamoto, T.; Kitazume, T. J. Org. Chem. 1989, 54, 83-91. For other examples on fluorinated aldehydes affording racemic fluorohydrins, see refs $6 \mathrm{~b}, 6 \mathrm{c}$, and (c) Borg, T.; Danielsson, J.; Mohiti, M.; Restorp, P.; Somfai, P. Adv. Synth. Catal. 2011, 353, 2022-2036.

(10) (a) Allen, A. E.; MacMillan, D. W. C. Chem. Sci. 2012, 3, 633658. (b) Du, Z.; Shao, Z. Chem. Soc. Rev. 2013, 42, 1337-1378. (c) Inamdar, S. M.; Shinde, V. S.; Patil, N. T. Org. Biomol. Chem. 2015, 13, 8116-8162. For selected reviews on metal-catalyzed polyols synthesis, see: (d) Herkommer, D.; Schmalzbauer, B.; Menche, D. Nat. Prod. Rep. 2014, 31, 456-467. (e) Dechert-Schmitt, A-M. R.; Schmitt, D. C.; Gao, X.; Itoh, T.; Krische, M. J. Nat. Prod. Rep. 2014, 31, 504513. (f) Kumar, P.; Tripathi, D.; Sharma, B. M.; Dwivedi, N. Org. Biomol. Chem. 2017, 15, 733-761.

(11) For the method used for the aldehyde fluorination, see: (a) Marigo, M.; Fielenbach, D.; Braunton, A.; Kjaersgaard, A.; Jørgensen, K. A. Angew. Chem., Int. Ed. 2005, 44, 3703-3706. For related aminocatalyzed fluorination methodologies, see: (b) Beeson, T. D.; MacMillan, D. W. C. J. Am. Chem. Soc. 2005, 127, 8826-8828. (c) Enders, D.; Hüttl, M. R. M. Synlett 2005, 2005, 0991-0993. (d) Steiner, D. D.; Mase, N.; Barbas, C. F., III. Angew. Chem., Int. Ed. 2005, 44, 3706-3710. For cascades or one-pot reactions based on aldehyde fluorination, see: (e) Huang, Y.; Walji, A. M.; Larsen, C. H.; MacMillan, D. W. C. J. Am. Chem. Soc. 2005, 127, 15051-15053. (f) Jiang, H.; Falcicchio, A.; Jensen, K. L.; Paixao, M. W.; Bertelsen, S.; Jørgensen, K. A. J. Am. Chem. Soc. 2009, 131, 7153-7157. (g) Appayee, C.; Brenner-Moyer, S. E. Org. Lett. 2010, 12, 3356-3359.

(12) See the Supporting Information (SI) for details.

(13) For reviews, see: (a) Pan, Y.; Tan, C.-H. Synthesis 2011, 2011 (13), 2044-2053. (b) Wang, Z. L. Adv. Synth. Catal. 2013, 355, 27452755. (c) Nakamura, S. Org. Biomol. Chem. 2014, 12, 394-405.

(14) (a) Rohr, K.; Mahrwald, R. Org. Lett. 2011, 13, 1878-1880. (b) Zheng, Y.; Xiong, H. Y.; Nie, J.; Hua, M. Q.; Ma, J. A. Chem. Commun. 2012, 48, 4308-4310. (c) Zhong, F.; Yao, W.; Dou, X.; Lu, Y. Org. Lett. 2012, 14, 4018-4021. (d) Bae, H. Y.; Sim, J. H.; Lee, J. W.; List, B.; Song, C. E. Angew. Chem., Int. Ed. 2013, 52, 1214312147.

(15) For selected examples of Lewis acid catalyzed decarboxylative reactions, see: (a) Lalic, G.; Aloise, A. D.; Shair, M. D. J. Am. Chem. Soc. 2003, 125, 2852-2853. (b) Orlandi, S.; Benaglia, M.; Cozzi, F. Tetrahedron Lett. 2004, 45, 1747-1749. (c) Magdziak, D.; Lalic, G.; Lee, H. M.; Fortner, K. C.; Aloise, A. D.; Shair, M. D. J. Am. Chem. Soc. 2005, 127, 7284-7285. (d) Fortner, K. C.; Shair, M. D. J. Am. Chem Soc. 2007, 129, 1032-1033. (e) Yin, L.; Kanai, M.; Shibasaki, M. J. Am. Chem. Soc. 2009, 131, 9610-9611. (f) Xiong, H.-Y.; Yang, Z.-Y.; Chen, Z.; Zeng, J- L.; Nie, J.; Ma, J.-A. Chem. - Eur. J. 2014, 20, 8325-8329. (g) Quintard, A.; Rodriguez, J. Chem.-Eur. J. 2015, 21, 1471714722. (h) Quintard, A.; Rodriguez, J. Chem. Commun. 2015, 51, 9523-9526.

(16) Franzén, J.; Marigo, M.; Fielenbach, D.; Wabnitz, T. C.; Kjærsgaard, A.; Jørgensen, K. A. J. Am. Chem. Soc. 2005, 127, 1829618304 .

(17) The X-ray structures were deposited on the Cambridge database under Nos. CCDC 1541884 and CCDC 1541885.

(18) Magnuson, S. R. Tetrahedron 1995, 51, 2167-2213

(19) (a) Mikami, K.; Matsukawa, S.; Nagashima, M.; Funabashi, H.; Morishima, H. Tetrahedron Lett. 1997, 38, 579-582. (b) Ji, C.; Peng, Y.; Huang, C.; Wang, N.; Jiang, Y. Synlett 2005, 2005 (6), 0986-0990. (c) Gryko, D.; Lipinski, R. Eur. J. Org. Chem. 2006, 2006, 3864-3876. (d) Hu, S.; Jiang, T.; Zhang, Z.; Zhu, A.; Han, B.; Song, J.; Xie, Y.; Li, W. Tetrahedron Lett. 2007, 48, 5613-5617. (e) Boughton, B. E. Griffin, M. D. W.; O'Donnell, P. A.; Dobson, R. C. J.; Perugini, M. A.; Gerrard, J. A.; Hutton, C. A. Bioorg. Med. Chem. 2008, 16, 9975-9983. (f) Ramachary, D. B.; Mondal, R.; Madhavachary, R. Org. Biomol. Chem. 2012, 10, 5094-5101. (g) Shimoda, Y.; Kubo, T.; Sugiura, M.; Kotani, S.; Nakajima, M. Angew. Chem., Int. Ed. 2013, 52, 3461-3464. (h) Valero, G.; Ribo, J. M.; Moyano, A. Chem.-Eur. J. 2014, 20, 17395-17408. (i) Kucherenko, A. S.; Gerasimchuk, V. V.; Lisnyak, V. G.; Nelyubina, Y. V.; Zlotin, S. G. Eur. J. Org. Chem. 2015, 2015, 5649-5654. (j) Kotani, S.; Kai, K.; Shimoda, Y.; Hu, H.; Gao, S.; Sugiura, M.; Ogasawara, M.; Nakajima, M. Chem.-Asian J. 2016, 11, $376-380$ and ref $15 \mathrm{~g}$ )

(20) The use of malonic acid half benzyl-thioster as a nucleophile under the reported conditions also only led to poor yield $(<20 \%$ yield by crude NMR analysis).

(21) See, for example: (a) Wang, Z.; Deschenes, D. J. Am. Chem. Soc. 1992, 114, 1090-1091. (b) Zhang, Y.; Arpin, C. C.; Cullen, A. J.; Mitton-Fry, M. J.; Sammakia, T. J. Org. Chem. 2011, 76, 7641-7653. (c) Shepherd, J. N.; Na, J.; Myles, D. C. J. Org. Chem. 1997, 62, 45584559. (d) Hartmann, E.; Oestreich, M. Org. Lett. 2012, 14, 24062409.

(22) Keto-acid fluorination is known; see: Li, J.; Li, Y.-L.; Jin, N.; Ma, A.-L.; Huang, Y.-N.; Deng, J. Adv. Synth. Catal. 2015, 357, 2474-2478. 